\title{
Behaviour informatics: data integration for greater understanding of human and animal behaviour
}

\author{
Ansgar Koene \\ From Twenty First Annual Computational Neuroscience Meeting: CNS*2012 \\ Decatur, GA, USA. 21-26 July 2012
}

Here we propose the establishment of a new addition to the current efforts in neuro-informatics aimed at an integrated study of the manly levels of human and animal behaviour. This new platform, which we call Behaviour Informatics, will facilitate the accumulation and sharing of behavioural data, and related analysis tools. Various Neuroinformatics platforms have in recent years been established to facilitate data sharing and integration for digital atlases of brain structure and anatomy, for fMRI and electrophysiology data, for modeling of spiking neural networks and many more. These Neuroinformatics efforts promise to provide a more coherent picture of the complete brain architecture. Similar efforts in behavioural studies would facilitate a more complete understanding of the relation between behavioural traits at the micro and macro levels and their dependence on environmental conditions. In addition to the pooling and standardization of data from behavioural experiments, another pillar of behaviour informatics could be a concerted effort to use virtual environments, like massively multi player games, to gather information on human behaviour in complex dynamic (social) environments with relatively minimal effort.

In this poster I will present the goals and general framework that will form the basis of the roadmap for the creation of a Behaviour Informatics platform that will be discussed in the workshop: Behaviour Informatics: data bases, data mining and virtual world behaviour.

Published: 16 July 2012

Correspondence: arkoene@gmail.com

Brain Science Institute, RIKEN, Wako-shi, Saitama 351-0198, Japan
doi:10.1186/1471-2202-13-S1-P105

Cite this article as: Koene: Behaviour informatics: data integration for greater understanding of human and animal behaviour. $B M C$ Neuroscience 2012 13(Suppl 1):P105.

Submit your next manuscript to BioMed Central and take full advantage of:

- Convenient online submission

- Thorough peer review

- No space constraints or color figure charges

- Immediate publication on acceptance

- Inclusion in PubMed, CAS, Scopus and Google Scholar

- Research which is freely available for redistribution 